\title{
Modeling Actuation Forces and Strains in Nastic Structures
}

\author{
Luke A. Matthews, Victor Giurgiutiu \\ Mechanical Engineering, University of South Carolina, 300 Main Street, Columbia, SC, 29208
}

\begin{abstract}
Nastic structures are capable of three dimensional shape change using biological principles borrowed from plant motion. The plant motor cells increase or decrease in size through a change in osmotic pressure. When nonuniform cell swelling occurs, it causes the plant tissue to warp and change shape, resulting it net movement, known as nastic motion, which is the same phenomena that causes plants to angle their broad leaf and flower surfaces to face light sources.

The nastic structures considered in this paper are composed of a bilayer of microactuator arrays with a fluid reservoir in between the two layers. The actuators are housed in a thin plate and expand when water from the fluid reservoir is pumped into the actuation chamber through a phospholipid bilayer with embedded active transport proteins, which move the water from the low pressure fluid reservoir into a high pressure actuation chamber. Increasing water pressure inside the actuator causes lateral expansion and axial bulging, and the non-uniform net volume change of actuators throughout the nastic structure results in twisting or bending shape change. Modifying the actuation displacement allows controlled volume change. This paper presents an analytical model of the driving and blocking forces involved in actuation, as well as stress and strain that occurs due to the pressure changes. Actuation is driven by increasing osmotic pressure, and blocking forces are taken into consideration to plan actuator response so that outside forces do not counteract the displacement of actuation. Nastic structures are designed with use in unmanned aerial vehicles in mind, so blocking forces are modeled to be similar to in-flight conditions. Stress in the system is modeled so that any residual strain or lasting deformation can be determined, as well as a lifespan before failure from repeated actuation. The long-term aim of our work is to determine the power and energy efficiency of nastic structures actuation mechanism.
\end{abstract}

Keywords: nastic structures; induced_strain actuation; active materials; smart structures; biotransport; ion pumps; ATP, SUT-4, transport protein; osmotic pressure; phospholipid bilayer

\section{INTRODUCTION}

Although plants are known for being stationary organisms, they have the ability to gradually move certain tissue to help sustain and procreate life. Plants use a process known as nastic motion to open flower petals and move their stems. Even though plant motility is limited, it enables flowers to pollinate and germinate seeds for future botanical generations and allows leaves to maximize their surface facing the sun to attain more solar energy for photosynthesis. Plants use motor cells that swell in size and act like muscles to cause local tissue expansion, causing bending deformation and overall plant tissue rotational or translational displacement.

The possibility of constructing a smart material composed of hydraulic microactuators that imitate nastic motor cells and use the same biological energy and power sources has been investigated in ref. [1] [2]. The biological energy for nastic movement is supplied by adenosine triphosphate (ATP) hydrolysis and used by SUT-4 active transport proteins to pump water into the cell, increasing osmotic pressure and causing the cell to swell. The energetics of ATP hydrolysis and factors affecting energy release have been studied [3][4]. The process of active transport has also been researched to understand the mechanics and energetics of transmembrane molecular movement [5][6] [7][8][9].

Molecular transport experiments have been conducted to re-create a membrane using phospholipids and transport proteins extracted from plants [10][11]. Such membranes provide a means for creating a pressure gradient in nastic actuators, as well as a housing structure for the active transport proteins which power the osmotic pressure increase that causes nastic actuation. Further membrane studies have been conducted to examine the effects of sustaining a pressure gradient and forces fluid diffusion that occurs [12]. The collective work on the ATP hydrolysis, active transport proteins, and membrane diffusion has enabled a mathematical model of the conditions and energy required to power a biomimetic synthetic nastic actuator using processes found in plants. The energy supplied and used during nastic actuation as well as factors affecting the process are discussed.

The biological processes found in plant movement are used to cause mechanical work in synthetic nastic actuators. The actuator activates when an increase in internal osmotic pressure forces outward volume expansion. The system 
response has been modeled to predict a possible range of volume increase during actuation [2][13][14][15]. In this paper, the structure is examined quantitatively to determine the volume increase during actuation using analytical solutions [2][16][17]. Nonlinear displacement is also discussed to consider the structural behavior during actuation [18][19][20]. Finally, stress in the actuator and failure mechanics are discussed [21][22].

The goal of our study is to examine theoretically the plausibility of constructing a shape-changing material for use in unmanned aerial vehicles that actuates using biological processes.

\section{NASTIC MOVEMENTS IN PLANTS}

\section{Biological Nastic Movement}

Plants possess the ability to gradually move their stems and leaves through the process of nastic movement in order to reproduce and survive. When plant cells are stimulated, usually by light, the plant response includes opening flower petals and moving stems so that leaves will face sunlight. Nastic motions are necessary for flower petals to open for pollination and for plant leaves to face sunlight to maximize light exposure for photosynthesis. These tissue movements generally occur steadily over several minutes in the case of opening a flower petal, and up to several hours, in the case of leaves constantly adjusting to face the sun moving across the sky. In some extreme cases, carnivorous plants like the Venus flytrap respond to touch stimulus to use nastic motion to trap insect prey. These plants actuate their motor cells very rapidly, so nastic motion takes only seconds.

Plant motility is achieved through means of specialized motor cells that expand in size due to increased osmotic pressure. Motor cells are grouped together to act as muscles, and their layout and orientation determines what kind of movement they cause in the local plant tissue. Motor cells grouped in clusters cause rotational movement in flower petals and the jaws of the insectivorous Venus flytrap, while aligned motor cells cause translational and bending movement in the stems and leaves.

\section{Energy for Nastic Movement Supplied by ATP Hydrolysis}

Motor cells act like hydraulic microactuators because they respond to an outside stimulus by using biochemical energy to increase their interior pressure, resulting in mechanical work in the form of volume increase and overall tissue displacement from the net nastic movement of an array of motor cells. The source of energy is ATP hydrolysis, described by the reaction:

$$
A T P+H_{2} 0 \rightarrow A D P+P O_{4}^{2-}+\Delta G_{A T P H}
$$

In aquatic solutions, ATP undergoes hydrolysis to produce adenosine diphosphate and an inorganic phosphate molecule, as well as to release energy, $\Delta \mathrm{G}_{\mathrm{ATPH}}$. The amount of energy released during hydrolysis is dependent on the $\mathrm{pH}$ of the solution, temperature, and the molar concentrations of ATP, ADP, and $\mathrm{PO}_{4}{ }^{2-}$ :

$$
\Delta G_{\text {ATPH }}=\Delta G_{0}-R \cdot T\left[\ln \frac{[A D P]\left[P O_{4}^{2-}\right]}{[A T P]}+2 p H\right],(\mathrm{J} / \mathrm{mol})
$$

In Eq.(2), $\Delta \mathrm{G}_{0}$ is the Gibbes free energy released by hydrolysis under standard $\mathrm{pH}$ of 7 and equilibrium concentrations of product and reactant, and is equal to $-30.5 \mathrm{~kJ} / \mathrm{mol}$ of ATP hydrolyzed. Eq. (2) describes energy released per mole of ATP hydrolyzed, in $\mathrm{J} / \mathrm{mol}$.

The ratio of the molar concentration of the ATP hydrolysis products to reactant is referred to as the mass-action balance ratio:

$$
K_{M A}=\frac{[A D P]\left[P O_{4}^{2-}\right]}{[A T P]}
$$

The mass-action balance ratio determines how much energy is released per mole of ATP that is hydrolyzed. Because the mass-action balance ratio has a logarithmic relation to the corresponding energy rates, the following equation is used to express the mass-action balance ratio into a from similar to $\mathrm{pH}$, as $\mathrm{pH}=-\log [\mathrm{H}+]$. This simplifies the energetic equation and allows for the mass-action balance ratio and the hydrogen concentration to be analyzed in like form.

$$
\begin{gathered}
p K=\log K_{M A} \\
\Delta G_{\text {ATPH }}=\Delta G_{0}-R \cdot T[2.3 p K+2 p H],(\mathrm{J} / \mathrm{mol})
\end{gathered}
$$


The energy release is greatest when the $\mathrm{pH}$ level is high and the $\mathrm{pK}$ value is low. Introducing $\mathrm{H}+$ ions to the osmoticum lowers the $\mathrm{pH}$ level, reducing the amount of energy produced as ATP is hydrolyzed. Modifying the $\mathrm{pH}$ level of the solution is a feasible mechanism for controlling actuation by energy release limitation.

\section{Motor Cell Volume Change from Active Transport Proteins}

The majority of energy derived from ATP hydrolysis in plant cells is used by various transport proteins in the cell membrane. The cell membrane is a bilayer of phospholipids, composed of a hydrophilic phosphate head and a tail of two hydrophobic lipids. Water and other small molecules diffuse through the membrane naturally along a concentration gradient. However, when larger molecules are required for the cell's biological processes, or the osmotic pressure in the cell needs to increase, fluid is moved through the cell membrane and against a concentration gradient by active transport proteins. Such is the case of nastic motor cells. Active transport proteins are embedded in the cell membrane and function both as a gate and a fluid pump. The proteins require energy to do the work of pumping fluid from a low molar concentration area outside the membrane, $\mathrm{C}_{e}$, to a higher concentration inside the cell, $\mathrm{C}_{\mathrm{i}}$. As the difference in concentrations increases, so does the energy required for transporting one mole of fluid against the concentration gradient, as described by the relationship:

$$
\Delta E_{A T}=R \cdot T \ln \frac{C_{i}}{C_{e}},(\mathrm{~J} / \mathrm{mol})
$$

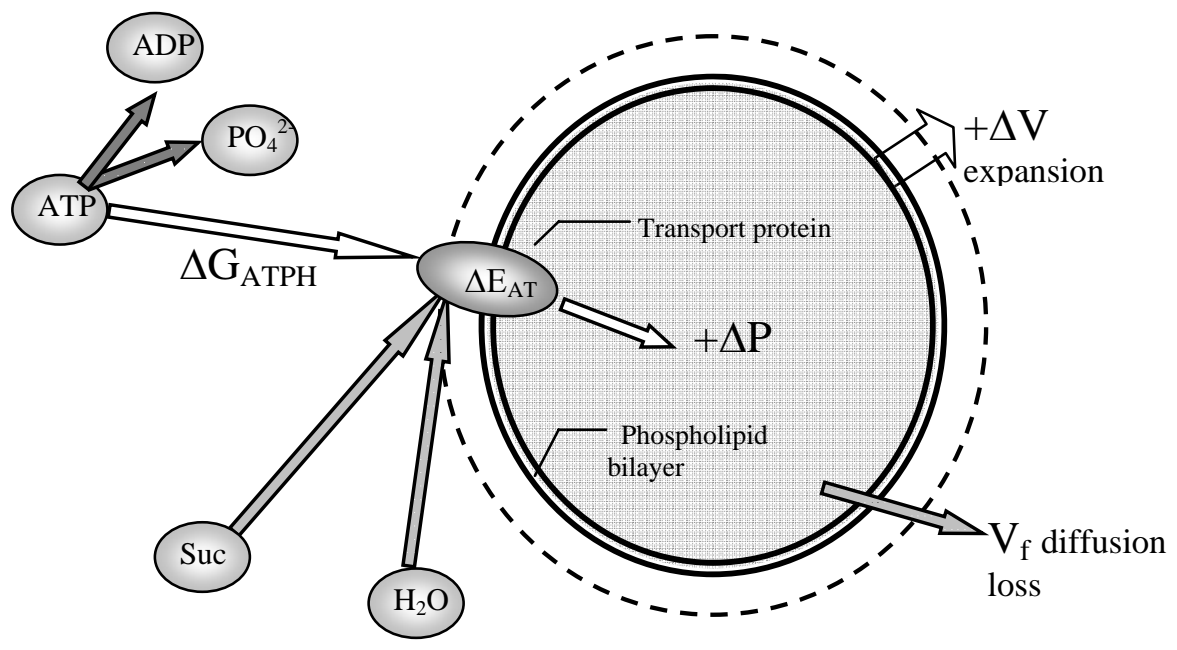

Figure 1: ATP hydrolysis supplies energy for transport proteins to pump fluid into motor cells, increasing osmotic pressure and cell volume.

\section{Volume Loss from Forced Diffusion}

Motor cells increase greatly in volume during nastic movement from increased osmotic pressure due to the active transport process. At the same time, the higher osmotic pressure forces water to diffuse through the membrane into a lower pressure area. The rate of cell volume change due to diffusion is expressed as:

$$
V_{f}=-P_{O S} \cdot S_{A} \cdot V_{W} \cdot\left(C_{i}-C_{e}\right)
$$

where $\mathrm{P}_{\mathrm{OS}}$ is the osmotic permeability of the membrane, $\mathrm{S}_{\mathrm{A}}$ is the surface area, $\mathrm{C}_{\mathrm{i}}$ and $\mathrm{C}_{\mathrm{e}}$ are the fluid concentrations of the cell interior and exterior, and $V_{W}$ is the partial molal volume of water $\left(18 \cdot 10^{-6} \mathrm{~m}^{3} / \mathrm{mol}\right)$. As the difference in concentrations $\Delta \mathrm{C}$ increases, the osmotic pressure inside the cell forces more water out of the cell by diffusion through the phospholipids in the cell membrane. Thus, during nastic movement and even after the motor cell has reached its intended size, active transport must be an ongoing process in order to keep the cell volume constant while it is losing fluid because of forced diffusion. 


\section{DESIGN OF A BIOMIMETIC NASTIC ACTUATOR}

\section{Design Principles for a Biomimetic Nastic Actuator}

Nastic structures are designed after shape-changing biological tissue found in plant leaves and stems. In plants, the motor cells that enable nastic motion are aligned in a plane. Likewise, nastic structures are a thin, deformable plate embedded with bioenergetically powered hydraulic microactuators that will fill with fluid and expand in size, imitating nastic motor cells. The actuators are cylindrical and enclosed by a thin cover plate at one end and a phospholipid membrane adjacent to a fluid reservoir on the other.

Biological motor cells and the nastic actuator both use a phospholipid bilayer membrane to create an osmotic gradient between the cell/actuator interior and the surrounding medium. In nastic structures, the membrane is formed from phospholipids extracted from plants, and work is currently underway to investigate reinforcing and polymerizing the membrane to increase material strength. Sucrose transport proteins, SUT-4, are embedded in the membrane to transport sucrose and water molecules from the fluid reservoir to the actuation barrel for osmotic pressure increase.

The fluid reservoir contains sucrose molecules and water for transport and a mix of ATP for hydrolysis to supply energy for the SUT-4 proteins. A feasible means of energy regulation is by means of the pH level of the solution. Introducing hydrogen ions or amino acid buffers modifies the $\mathrm{pH}$ level, which in turn affects the amount of energy released during ATP hydrolysis. Biochemical energy regulation is the proposed means of actuation control.
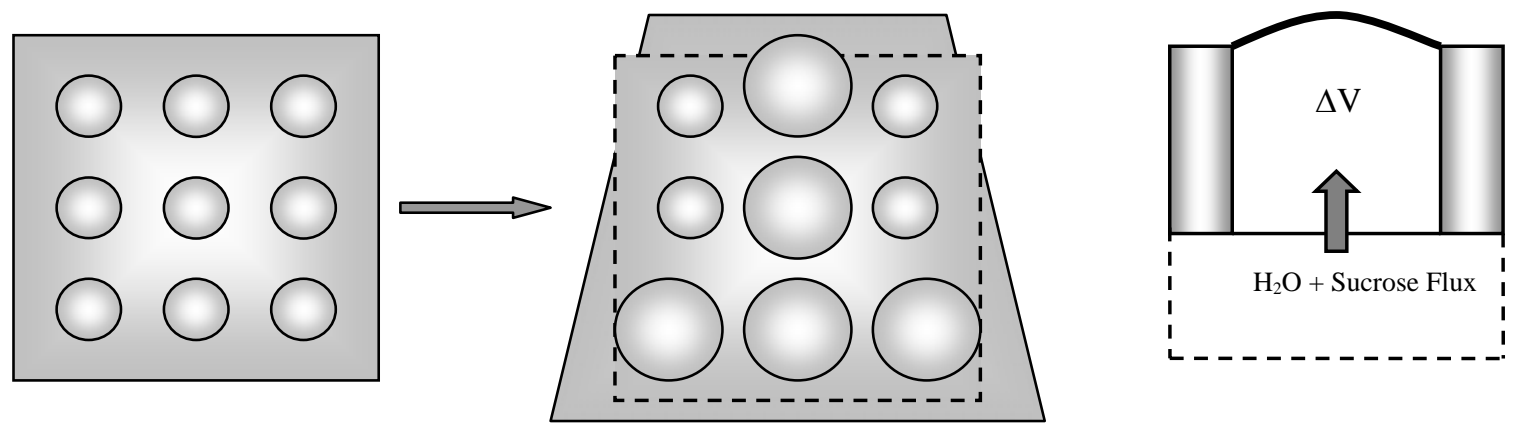

Figure 2: Nastic structure actuator array, example of shape change due to nonuniform deformation, and volume change in an individual actuator.

\section{Material and Dimensional Considerations}

Plant cells are limited in size because of active transport, which is the means by which cells get the majority of the nutrients they need for survival, as well as the mechanism that purges the cell of toxic byproducts that are too large to exit the cell by diffusion. As a cell grows, the volume of the cell increases faster than the surface area, and the cell requires more nutrients but has less membrane area and transport proteins to get the vital molecules into the cell. Thus, a plant cell is limited in size, as larger cells do not have the means to properly supply nutrients. A large membrane surface area-to-volume ratio is desired for efficiency in providing nutrients. Also, a small surface area membrane has greater structural integrity under stress than a larger membrane.

The nastic actuator is designed with these things in mind. It has the disadvantage of being cylindrical instead of spherical like plant cells, reducing the membrane surface area, but it does provide the advantage of having less area for diffusion, so less fluid is lost during actuation. The active transport rate is limited by surface area, but the amount of fluid lost due to diffusion is also minimized.

\section{Predicting Energy and Chemical Requirements Through a Bioenergetic Model}

The bioenergetics concerning biological nastic motion are analyzed to predict the energy requirements of active transport-powered actuation and the chemical condition needed to supply the energy. The desired pressure increase is 
known, and using Eq. (2) and (6) above allows the estimation of chemical conditions that allow for biomimetic nastic actuation to be possible.

Several conditions and assumptions must be clarified. The fluid reservoir will remain at a constant pressure of 1 $\mathrm{MPa}$, while the osmotic pressure in the actuator will increase from 1 to $5 \mathrm{MPa}$. As fluid flows from the reservoir into the actuator, the pressure will remain constant though fluid is being supplied. ATP hydrolysis is a reversible process when the enzyme ATPase is present in the solution; although the concentrations of ATP, ADP, and $\mathrm{PO}_{4}{ }^{2-}$ change during hydrolysis, the initial concentrations can be restored with little further energy requirements. The $\mathrm{pH}$ level can be raised and lowered by the introduction of $\mathrm{H}+$ ions and buffer amino acids. Temperature will be held constant at $300 \mathrm{~K}$, but atmospheric temperature conditions will be discussed later in the paper.

Molar concentration will be considered as pressure using the equation:

$$
P=C_{\text {mol }} \cdot R \cdot T
$$

For active transport to occur and actuation to be possible, the hydrolysis energy supplied must meet the active transport energy requirements, which depend on the difference in osmotic pressures in the fluid reservoir and the actuator. Rearranging Eq.(2), using the ratio of (3) and the energy determined by Eq. (6), the chemical conditions that will provide enough energy for active transport is found to be:

$$
K_{M A}=\exp \left[\frac{\Delta E_{A T}-\Delta G_{0}}{-R \cdot T}-2 \cdot p H\right]
$$

The same equations can be rearranged differently to find the possible pressure change in the actuator from ATP hydrolysis-fueled active transport, dependent on chemical conditions:

$$
P_{A}=P_{f} \exp \left[\frac{\Delta G_{0}}{R \cdot T}-2.3 p K+2 p H\right]
$$

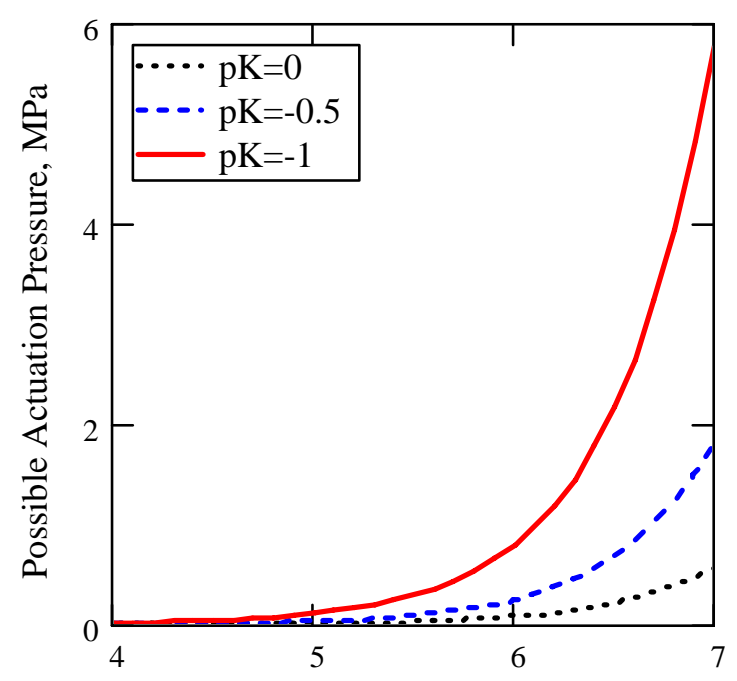

Reservoir $\mathrm{pH}$

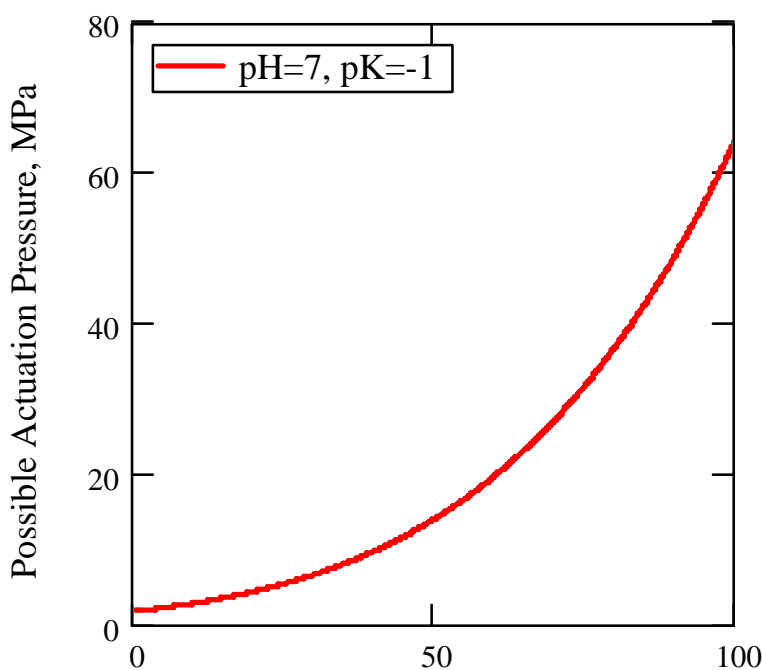

Revervoir Temperature, C

Figure 3: The osmotic pressure increase in the actuator dependent on the chemical and physical conditions of the fluid reservoir, where ATP hydrolysis occurs.

\section{Influence of Temperature on Bioenergetics}

There is interest in using nastic materials in unmanned aerial vehicles (UAV), so it is important to consider the effect that atmospheric temperature will have on the energy produced by ATP hydrolysis and used in active transport during actuation. As altitude increases, the temperature decreases. The energy released by hydrolysis decreases with temperature, so actuation rates would decrease the higher an UAV flies. However, a UAV designed with a heat sink 
from an electric or mechanical component adjacent to the nastic material could increase the energy release rate, allowing for quicker actuation.

\section{Energy for Sustained Actuation}

When actuation begins, the pressure difference between the actuation barrel and the fluid reservoir will cause diffusion across the membrane and into the reservoir. The diffusion rate of moles of fluid lost is expressed as a modified version of Eq.(7):

$$
\Delta f_{m o l}=-P_{O S} \cdot A_{s} \cdot V_{W}\left[\frac{P_{A}-P_{f}}{R \cdot T}\right] \cdot C_{m o l}
$$

where $\mathrm{C}_{\mathrm{mol}}$ is a coefficient to convert the flux from a volume transfer rate to mole of fluid diffused over time. Values for $\mathrm{P}_{\mathrm{OS}}$ were taken from experiments with root cells (ref) and used in diffusion modeling. Because the flux is expressed as moles diffused per second, Eq. (6) can be used to determine the additional energy required to sustain a constant pressure in the actuator, thus sustaining the final static actuation volume.

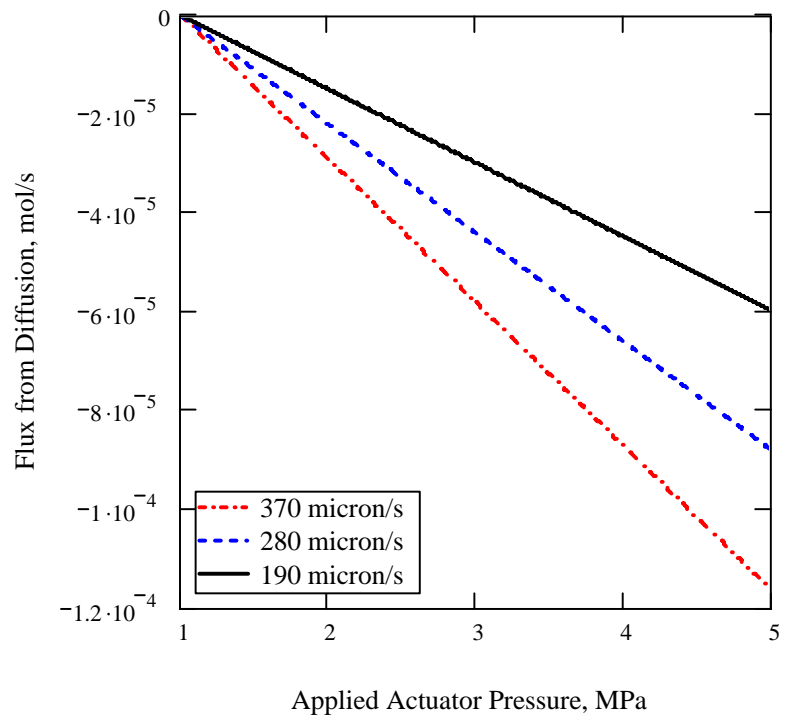

Figure 4: Rate of forced diffusion due to increased pressure in the actuator barrel (radius=250 microns), dependent on the osmotic permeability of the membrane.

Table 1: Fluid and chemical properties affecting actuation bioenergetics

\begin{tabular}{ll}
\hline Property & Value \\
\hline $\mathrm{R}$, Universal gas constant & $8.31447 \mathrm{~L}^{*} \mathrm{kPa} / \mathrm{mol}^{*} \mathrm{~K}$ \\
$\mathrm{~V}_{\mathrm{w}}$, Partial molality of water & $18.05^{*} 10^{-6} \mathrm{~m} 3 / \mathrm{mol}$ \\
$\mathrm{C}_{\text {mol }}$ Molar flux conversion coefficient & $55366.11 \mathrm{~mol} / \mathrm{m}_{3}$ \\
$\mathrm{P}_{\mathrm{OS}}$, Membrane permeability & $190 \rightarrow 370 \mathrm{micron} / \mathrm{s}$, default $=280$ \\
& $\mathrm{micron} / \mathrm{s}$ \\
$\mathrm{P}_{\mathrm{a}}$, Applied osmotic pressure & $1 \rightarrow 5 \mathrm{MPa}$, default $=5 \mathrm{MPa}$ \\
$\mathrm{P}_{\mathrm{f}}$, Fluid reservoir pressure & $1 \mathrm{MPa}$ \\
$\mathrm{pH}$ & $4 \rightarrow 7$, default $=7$ \\
$\mathrm{~K}_{\mathrm{MA}}$, Mass action balance ratio & $0 \rightarrow 0.37$, default $=0.36$ \\
$\mathrm{pK}$, -log[K & $-1 \rightarrow 0$, default $=-1$ \\
$\mathrm{~T}$, absolute temperature & $0 \rightarrow 100 \mathrm{C}$, default $=27 \mathrm{C}$ \\
\hline
\end{tabular}




\section{MECHANICAL RESPONSE TO BIOMIMETIC NASTIC ACTUATION}

\section{Mechanical Response during Actuation}

As the pressure inside the actuator increases, the fluid pushes outward on the walls of the chamber. It is assumed that the membrane is reinforced, so outward bulging into the fluid reservoir is neglected. The net volume change, $\Delta \mathrm{V}_{\text {ISA }}$, is the sum of volume changes due to fluid compressibility, barrel wall expansion, cover plate deformation, and outside blocking loads that act against outward displacement, expressed as:

$$
\Delta V_{\text {ISA }}=\Delta V_{f c}+\Delta V_{b e}+\Delta V_{c p}-\Delta V_{\text {load }}
$$

The volume increment due to fluid compressibility and barrel expansion are discussed quantitatively in (reference two previous papers) and shown to be much smaller than the volume increase than the blister profile created from the cover plate's outward deformation. Because the cover plate displacement is the greatest volume increment during actuation, it is analyzed in further detail in order to understand the effect of outside blocking forces, displacement rates, and stress from osmotic pressure increase. The following table summarizes the material properties and physical dimensions used during actuation analysis.

Table 2: Actuator properties and dimensions

\begin{tabular}{ll}
\hline Property & Value \\
\hline r, Actuator radius & $25 \rightarrow 500$ micron, default $=250$ micron \\
$\mathrm{S}_{\mathrm{a}}$, Membrane surface area & $1963 \rightarrow 785^{*} 10^{3}$ micron $^{2}$ \\
t, plate thickness & $23 \rightarrow 150$ micron, default $=23$ micron \\
E, Modulus of elasticity & $1 \rightarrow 5 \mathrm{MPa}$, default $=5 \mathrm{MPa}$ \\
v, Poisson's ratio & $0.3 \rightarrow 0.45$, default $=0.34$ \\
\hline
\end{tabular}

\section{Cover Plate Displacement and Blocking Forces}

As osmotic pressure is increased, the actuator cover plate bulges outward, forming a blister profile. The analytical solution to the bending of a clamped circular thin plate is used to determine the displacement, and integrated to find the volume increment from the bending deformation.

$$
\begin{gathered}
u_{C P}=\frac{P_{A} \cdot r^{4} \cdot 3\left(1-v^{2}\right)}{16 \cdot E \cdot t^{3}} \\
\Delta V_{C P}=2 \pi \int_{0}^{r} r \cdot u_{C P} d r=\frac{P_{A} \cdot \pi \cdot r^{6}\left(1-v^{2}\right)}{16 \cdot E \cdot t^{3}}
\end{gathered}
$$

\section{Nonlinear Displacement Analysis for Volume Increase}

The displacement of the cover plate changes from a bending plate to a stretching membrane as the applied osmotic pressure increases. Because of this, there is a nonlinear relationship between the pressure and the volume increment during actuation. Non-dimensional analysis is used to determine the range of pressure that produces bending deformation in the plate and the transition pressure where the plate begins to act as a stretching membrane.

The applied osmotic pressure is defined as dimensionless using the equation:

$$
\rho=\frac{6\left(1-v^{2}\right) P_{A} \cdot r^{4}}{E \cdot t^{4}}
$$

The central deflection in dimensionless analysis is dependent on initial membrane stress, B. Because the plate is clamped and made of the same material as the actuator housing plate, the initial membrane stress is evaluated at a low value, approaching zero. The central deflection and the blister volume of the cover plate is described by:

$$
\begin{aligned}
& W_{0}=\frac{P_{A}}{2}\left[\frac{2\left[1-I_{0}(\beta)\right]}{\beta^{3} \cdot I_{1}(\beta)}+\frac{1}{\beta^{2}}\right] \\
& V_{B}=\frac{P_{A}}{\beta^{2}}\left[\frac{2}{\beta^{2}}+\frac{1}{4}-\frac{I_{0}(\beta)}{\beta \cdot I_{1}(\beta)}\right]
\end{aligned}
$$


If pre-actuation stress is introduced into the plate, the deformation behavior would shift from predominately bending to stretching as B increases. In Eq. (16) and (17), $\mathrm{I}_{0}$ and $\mathrm{I}_{1}$ refer to modified Bessel functions.

Non-dimensional analysis shows that during the beginning of actuation, the plate experiences linear bending deformation. However, the deformation quickly begins a transition to stretching behavior and approaches a cubic asymptote. The nonlinear deformation indicates that the volume increase will be greater than it would be with linear deformation.

Table 3: Normalized and dimensionless values for nonlinear cover plate displacement

\begin{tabular}{|c|c|c|}
\hline Property & Actual Range & Dimensionless Range \\
\hline Applied pressure & $\mathrm{P}_{\mathrm{A}}=0 \mathrm{MPa} \rightarrow 5 \mathrm{MPa}$ & $\rho=0 \rightarrow 97.719$ \\
\hline Plate deflection & $\mathrm{u}_{\mathrm{CP}}=0 \rightarrow 70.2$ micron & $\mathrm{W}_{0}=3.063$ \\
\hline Volume increment & $\Delta \mathrm{V}_{\mathrm{CP}}=0 \rightarrow 4597 \mathrm{pL}$ & $V_{B}=1165$ \\
\hline $\begin{array}{l}\text { Pressure range causing linear } \\
\text { bending deflection }\end{array}$ & $0 \rightarrow 0.48 \mathrm{MPa}$ & $0 \rightarrow 9.381$ \\
\hline $\begin{array}{l}\text { Pressure range causing non- } \\
\text { linear deflection }\end{array}$ & $0.48 \rightarrow 4.897 \mathrm{MPa}$ & $9.381 \rightarrow 95.706$ \\
\hline $\begin{array}{l}\text { Pressure range causing cubic } \\
\text { deflection }\end{array}$ & $4.897 \rightarrow 5 \mathrm{MPa}$ & $95.706 \rightarrow 97.719$ \\
\hline
\end{tabular}

\section{Stress and Crack Propagation during Actuation}

To ensure that the actuator does not fail during usage, stress analysis is conducted. The stress present in the cover plate is dependent on the radius and thickness. Increasing the thickness of the plate decreases the deflection potential, but will also lower the stress levels, providing a margin of safety against failure. The biaxial stress in the cover plate while deformed by osmotic pressure is given by:

$$
\sigma_{0}=0.431 \sqrt[3]{P_{A}^{2} \cdot \frac{r^{2}}{t^{2}}}
$$

When the plate is stretched to the point of reaching a critical level of stress, crack propagation occurs. Initially, cracks form independently, but grow as stress in the plate is maintained or increased. Eventually, cracks will grow together into a network, severely compromising the structural integrity of the plate and causing ultimate failure of the actuator. The energy release rate of an individual growing crack has been determined to be:

$$
G=\frac{1}{2} \frac{\left(1-v^{2}\right) t \cdot \sigma^{2}}{E} \pi \cdot g(\alpha, \beta)
$$

The value $g(\alpha, \beta)$ is a non-dimensional crack opening displacement integer that is dependent on Dundur's two parameters, $\alpha$ and $\beta$. The displacement integer is determined by differences in the film under stress and the substrate. In the case of nastic actuators, the cover plate and housing substrate are made of the same material, so $\alpha=\beta=0$, and $g(\alpha, \beta)=(1.1215)^{2}$. The graphs in Figure 5 summarize the stress present in the cover plate when actuation pressure is applied, and the energy release rate during plate cracking.

Related studies on thin films subjected to repeated loading have shown that creep is present after each loading cycle. When the biaxial stress in the plate increases, plastic strain remains after the pressure is removed. Further studies planned include repeated loading analysis to determine the rate of residual stress accumulation and how many actuation cycles can be applied before material fatigue and failure. 


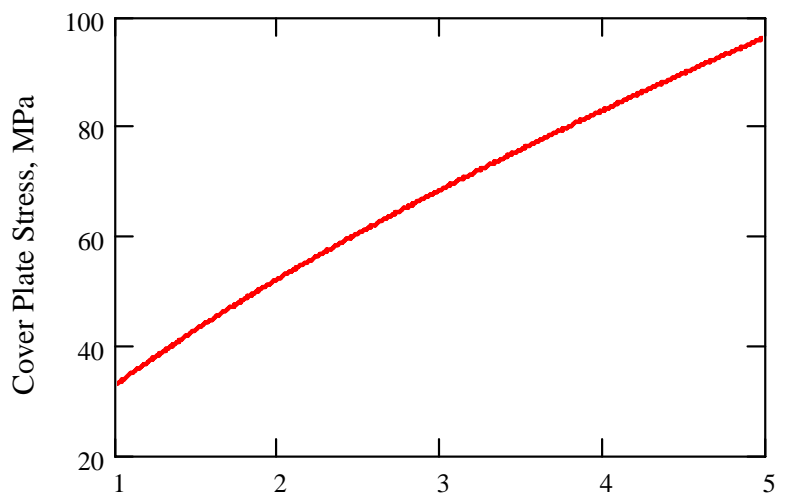

Actuator Pressure, MPa

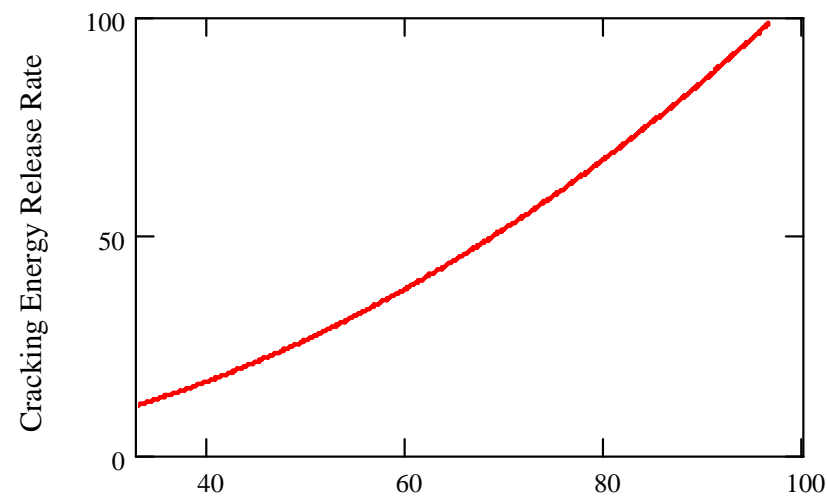

Cover Plate Stress

Figure 5: The stress in the cover plate during actuation and energy release rate when crack propagation begins.

\section{SUMMARY}

The bioenergetics that power nastic movement in plants is examined to predict the feasibility of constructing a synthetic biomimetic nastic material. It is shown theoretically to be possible to utilize ATP hydrolysis to enable fluid transport through a phospholipid membrane. ATP hydrolysis is a renewable, efficient biological energy source for active transport to increase osmotic pressure, which is the driving force of for nastic actuation. The energy release and consumption is examined to determine the chemical and fluid conditions that will make nastic actuation possible.

The mechanical response of the nastic actuator is modeled and analyzed to predict the possible volume increases and non-linear expansion rates. Strain and crack propagation are also investigated to estimate the adverse effects the actuation pressure has on the system. Further studies are planned to measure residual stress and plastic strain in the material after actuation, as well as determining a life expectancy for cyclic stress.

\section{ACKNOWLEDGEMENTS}

This research is supported by DARPA, with Dr. Main as the Nastic Structures project supervisor. The authors also wish to thank our research collaborators at the Virginia Tech Center for Intelligent Materials and Smart Systems (CIMSS), the University of Cincinnati Department of Molecular and Cellular Biology, and Stanford Research Institute (SRI).

\section{REFERENCES}

[1] Leo, D., Sundaresan, V.B., Tan, H., Cuppoletti, J., Investigation on High Energy Density Materials Utilizing Biological Transport Mechanisms, Proceedings of ASME International Mechanical Engineering Conference \& Exposition, November 13-20, 2004, Anaheim, CA. ASME-IMECE2004-60714

[2] Giurgiutiu, V., Leo, D., Sundaresan, V.B., Matthews, L., Concepts for Energy and Power Analysis in Nastic Structures. Proceedings of ASME International Mechanical Engineering Conference \& Exposition, November 511, 2005, Orlando, FL. ASME-IMECE2005-82786

[3] Nelson. D., Cox, M., Lehninger Principles of Biochemistry, Worth Publishers, 2000.

[4] Segel, I., Biochemical Calculations- How to Solve Mathematical Problems in Biochemistry, John Wiley \& Sons, Inc., 1976.

[5] Morillon, R., Lienard, D., Chrispeels, M., Lassalles, J., Rapid Movements of Plants Organs Require Solute-Water Cotransporters or Contractile Proteins, Plant Physiology 127: p.720-723, 2001. 
[6] Hope, A.B., Ion Transport and Membranes- A Biophysical Outline, University Park Press, Baltimore, 1971.

[7] Quastel, J.H., Transport at Cell Membranes and Regulation of Cell Metabolism, Membrane Transport and Metabolism, Czechoslovak Academy of Sciences, 1960.

[8] Morillon, R., Lienard, D., Chrispeels, M., Lassalles, J.P., Rapid Movements of Plant Organs Require Solute-Water Cotransporters or Contractile Proteins, Plant Physiology 127, p.720-723, 2001.

[9] Bush, D.R., Electrogenicity, pH-Dependence, and Stoichiometry of the Proton-Sucrose Symport, Plant Physiology 93, p.1590-1596, 1990.

[10] Leo, D., Sundaresan, V.B., Experimental Investigation for Chemo-Mechanical Actuation Using Biological Transport Mechanisms, Proceedings of ASME International Mechanical Engineering Conference \& Exposition, November 5-11, 2005, Orlando, FL. ASME-IMECE2005-81366

[11] Sundaresan V.B., Leo, D., Chemomechanical Model of Biological Membranes for Actuation Mechanisms, Proceedings of SPIE-2005 Smart Structures Conference, March 3-8, 2005, San Diego, CA. SPIE-5761-15

[12] Ramahaleo, T., Morillon, R., Alexandre, J., Lassalles, J.P., Osmotic Water Permeability of Isolated Protoplasts. Modifications During Development, Plant Physiology 119, p.885-896, 1999.

[13] Weiland, L., Homison, C., Coupled Transport/Hyperelastic Model for Nastic Materials, Proceedings of ASME International Mechanical Engineering Conference \& Exposition, November 5-11, 2005, Orlando, FL. ASMEIMECE2005-79387

[14] Maute, K., Dunn, M., Howard, M., Bischel, R., Pajot, J., Multiscale Design of Vascular Plates, Proceedings of ASME International Mehcanical Engineering Conference \& Exposition, November 5-11,2005, Orlando, FL, ASME-IMECE2005-82203

[15] Su, Y.C., Lin, L. Pisano, A.P., A Water-Powered Osmotic Microactuator, Journal of Microelectromechanical Systems 11, No.6, p.736-742, 2002.

[16] Timoshenko, S., Woinowsky-Krieger, S., Theory of Plates and Shells, McGraw-Hill, NY, 1959.

[17] Massonnet, C.G., “Two Dimensional Problems”, Chapter 37 in Handbook of Engineering Mechanics, W. Flugge (Ed.), McGraw-Hill, 1962.

[18] Wan, K., Lim, S., The Bending to Stretching Transition of a Pressurized Blister Test, International Journal of Fracture 92: L43-L47, 1998.

[19] Wan, K., Guo, S., Dillard, D., A Theoretical and Numerical Study of a Thin Clamped Circular Film Under An External Load in the Presence of a Tensile Residual Stress, Thin Solid Films 425, p.150-162, 2003.

[20] Cotterell, B., Chen, Z., The Blister Test- Transition from Plate to Membrane Behavior for an Elastic Material, International Journal of Fracture 86, p.191-198, 1997.

[21] Alaca, B.E., Selby, J.C., Saif, M.T.A., Sehitoglu, H., Biaxial Testing of Nanoscale Films of Compliant Substrates: Fatigue and Fracture, Review of Scientific Instruments 73, no.8, p.2963-2970, 2002.

[22] Beuth, J.L., Cracking of Thin Bonded Films in Residual Tension, International Journal of Solids and Structures 29, no. 12, p.1657-1675, 1992. 